\title{
EDITORIAL
}

\section{Ambient temperature, testosterone, and suicide}

\author{
Leo Sher ${ }^{1,2}$ iD
}

${ }^{1}$ James J. Peters Veterans' Administration Medical Center, Bronx, NY, USA. ${ }^{2}$ Icahn School of Medicine at Mount Sinai, New York, NY, USA.

Suicide is a significant medical and social problem around the world. ${ }^{1,2}$ It is estimated that over 800,000 people die by suicide each year around the globe and that there are many non-fatal suicide attempts for each suicide death. In some countries, suicide rates are increasing. ${ }^{1,2}$ For example, in the United States, the age-adjusted suicide rate increased $36.7 \%$ between 2000 and 2018 (10.4/ $100,000$ to $14.2 / 100,000)^{2}$

Multiple biological and psychological mechanisms are involved in the pathophysiology of suicide. ${ }^{1-4}$ For example, childhood traumatic experiences are a risk factor for non-suicidal self-injury and suicidal behavior. ${ }^{4}$ Meteorological influences such as the ambient temperature may affect human behavior, including suicidal behavior. ${ }^{5-8}$

Several research reports indicate that a higher ambient temperature is associated with an increased risk of suicide. ${ }^{5-8}$ Page et al. ${ }^{5}$ studied the relationship between daily suicide counts and temperature in England and Wales and found that above $18{ }^{\circ} \mathrm{C}$, each $1{ }^{\circ} \mathrm{C}$ increase in mean temperature was associated with a 3.8 and $5.0 \%$ rise in suicide and violent suicide, respectively. Using comprehensive data from multiple decades for both the United States and Mexico, Burke et al. ${ }^{6}$ found that suicide rates increase $0.7 \%$ in United States counties and $2.1 \%$ in Mexican municipalities for every $1{ }^{\circ} \mathrm{C}$ increase in monthly average temperature. Kim et al. ${ }^{7}$ examined the temperature-suicide relationship using data collected from multiple locations in 12 countries and found that the risk of suicide increased with the increasing ambient temperature. Kayipmaz et al. $^{8}$ found that an increase in the ambient temperature leads to an increase in the number of suicides in Turkey. It has been proposed that the association between higher ambient temperature and increased risk of suicide is related to alterations in the serotonergic system, including a decrease in the levels of I-tryptophan, a precursor for serotonin. ${ }^{5,7,8}$

It is interesting to hypothesize that changes in testosterone levels may mediate the effect of the ambient temperature on suicidal behavior. Several animal and human studies conducted over the past decades have shown that an increase in the ambient temperature reduces testosterone secretion. ${ }^{9-12}$ For example, Gomes et al. $^{9}$ observed that a high ambient temperature is

Correspondence: Leo Sher, James J. Peters VA Medical Center, 130 West Kingsbridge Road, Bronx, NY, 10468, USA.

E-mail: Leo.Sher@mssm.edu

Submitted Mar 16 2021, accepted Jun 10 2021, Epub Aug 092021. detrimental to testosterone secretion in rams. Gesquiere et al. $^{12}$ examined the effects of season and ambient temperature on testosterone levels in male baboons. The authors observed that testosterone levels were lower in months of high average daily maximum temperatures and suggested that their finding was a result of the direct impact of heat on testes. Some human studies have produced similar results. ${ }^{10,11}$ For example, a study of seasonal effects on blood testosterone concentration in a large sample of 32-44 y.o. U.S. military veterans found that testosterone levels peaked in December, a cold time of the year. ${ }^{10}$ Another research group reported that testosterone levels showed significant seasonal variation in men living in the north of Norway, with lower levels during the summer months. ${ }^{11}$

Several observations published over the past 15 years indicate that lower testosterone levels may be associated with suicidal behavior. ${ }^{13-16}$ In our study, we examined morning testosterone levels in male combat veterans with or without a history of suicide attempt. ${ }^{16}$ Free and total testosterone levels were lower in suicide attempters compared to non-attempters. In addition, both free and total testosterone levels negatively correlated with suicide ideation scale scores in the whole sample. Tripodianakis et al. ${ }^{13}$ compared total plasma testosterone levels in males with or without a recent history of suicide attempt. The authors found that attempters had significantly lower blood testosterone levels compared to non-attempters. Markianos et al. ${ }^{14}$ compared total plasma testosterone concentrations in male psychiatric patients who had attempted suicide by jumping from a high place, males who were hospitalized after accidentally falling from a height, and healthy controls. The researchers observed that, compared to the healthy control group, both accident and attempt groups had lower blood testosterone concentrations. They also found a trend towards lower testosterone concentrations in suicide attempters than the accident group. We also reported a case of a young combat veteran who presented with an impulsive suicide attempt that had a high potential for lethality and whose plasma testosterone level was low compared to established normal limits. ${ }^{15}$

It should be noted that some studies have found an association between higher levels of testosterone

How to cite this article: Sher L. Ambient temperature, testosterone, and suicide. Braz J Psychiatry. 2022;44:1-3. http://dx.doi.org/ 10.1590/1516-4446-2021-1887 
and suicidal behavior, especially impulsive suicide attempts. $^{17-19}$ It is probable that both high and low testosterone levels are associated with suicidality. ${ }^{19}$

The hypothesis that testosterone is involved in the effect of the ambient temperature on suicidality can be supported by the positive relationship between high ambient temperature and suicide attempts among males but not among females. ${ }^{20}$ Testosterone plays an important biological role in both males and females. ${ }^{21}$ However, testosterone levels are much higher in males than in females and, consequently, testosterone may play a bigger role in the relationship between the ambient temperature and suicidal behavior in men than in women.

The hypothalamic-pituitary-adrenal system may be involved in the relationship between ambient temperature, testosterone and suicidality because glucocorticoids regulate the hypothalamic-pituitary-gonadal axis at all levels. ${ }^{22,23}$ Glucocorticoids inhibit the release of gonadotropin-releasing hormone from the hypothalamus, inhibit gonadotropin synthesis and release in the pituitary, and inhibit testosterone synthesis and release in the gonads. ${ }^{22,23}$ Studies suggest that glucocorticoid levels increase as the ambient temperature rises. ${ }^{24-26}$ Consequently, testosterone levels decrease. Therefore, the hypothalamic-pituitary-adrenal system may be a mediator of the effect of ambient temperature on testosterone levels.

Multiple biological systems are probably involved in the effects of ambient temperature on suicidal behavior. Psychosocial factors may also partially mediate the effect of temperature changes on suicidality. The effects of ambient temperature on suicide risk are an understudied and underappreciated area of suicidology.

Individuals with depressive and/or psychotic symptoms are at elevated suicide risk. ${ }^{3,27} \mathrm{~A}$ history of suicide attempt predicts future suicide attempts and death by suicide. $^{28,29}$ For example, a 5-year follow-up of 302 individuals admitted to an inpatient psychiatric unit after high-lethality suicide attempts showed that $37 \%$ of these individuals made at least one further suicide attempt, and $6.7 \%$ eventually died by suicide. ${ }^{29}$ Clinicians must understand that depressed and psychotic individuals and persons with a history of suicidal behavior need to be carefully evaluated for suicidality when the ambient temperature significantly increases. Future studies of the relation between ambient temperatures and suicide risk may help clarify the pathophysiology of suicide and lead to new suicide prevention interventions.

\section{Disclosure}

The author reports no conflicts of interest.

\section{References}

1 World Health Organization (WHO). Preventing suicide: a global imperative. Geneva: WHO; 2014.

2 Mann JJ, Michel CA, Auerbach RP. Improving suicide prevention through evidence-based strategies: a systematic review. Am J Psychiatry. 2021 Feb 18;appiajp202020060864. doi: 10.1176/appi.ajp. 2020.20060864. Online ahead of print.
3 Sher L. Resilience as a focus of suicide research and prevention. Acta Psychiatr Scand. 2019;140:169-80.

4 Serafini G, Canepa G, Adavastro G, Nebbia J, Murri MB, Erbuto D, et al. The relationship between childhood maltreatment and nonsuicidal self-injury: a systematic review. Front Psychiatry. 2017;8: 149.

5 Page LA, Hajat S, Kovats RS. Relationship between daily suicide counts and temperature in England and Wales. $\mathrm{Br} J$ Psychiatry. 2007;191:106-2.

6 Burke M, González F, Baylis P, Heft-Neal S, Baysan C, Basu S, et al. Higher temperatures increase suicide rates in the United States and Mexico. Nat Clim Chang. 2018;8:723-9.

7 Kim Y, Kim H, Gasparrini A, Armstrong B, Honda Y, Chung Y, et al. Suicide and ambient temperature: a multi-country multi-city study. Environ Health Perspect. 2019;127:117007.

8 Kayipmaz S, San I, Usul E, Korkut S. The effect of meteorological variables on suicide. Int J Biometeorol. 2020;64:1593-8.

9 Gomes WR, Butler WR, Johnson AD. Effect of elevated ambient temperature on testis and blood levels and in vitro biosynthesis of testosterone in the ram. J Anim Sci. 1971;33:804-7.

10 Dabbs JM Jr. Age and seasonal variation in serum testosterone concentration among men. Chronobiol Int. 1990;7:245-9.

11 Svartberg J, Midtby M, Bønaa KH, Sundsfjord J, Joakimsen RM, Jorde $R$. The associations of age, lifestyle factors and chronic disease with testosterone in men: the Tromsø Study. Eur J Endocrinol. 2003;149:145-52.

12 Gesquiere LR, Onyango PO, Alberts SC, Altmann J. Endocrinology of year-round reproduction in a highly seasonal habitat: environmental variability in testosterone and glucocorticoids in baboon males. Am J Phys Anthropol. 2011;144:169-76.

13 Tripodianakis J, Markianos M, Rouvali O, Istikoglou C. Gonadal axis hormones in psychiatric male patients after a suicide attempt. Eur Arch Psychiatry Clin Neurosci. 2007;257:135-9.

14 Markianos M, Tripodianakis J, Istikoglou C, Rouvali O, Christopoulos $\mathrm{M}$, Papageorgopoulos $\mathrm{P}$, et al. Suicide attempt by jumping: a study of gonadal axis hormones in male suicide attempters versus men who fell by accident. Psychiatry Res. 2009;170:82-5.

15 Kiraly DD, Sher L. Low testosterone in a young combat veteran with dual diagnosis and suicidal behavior: a case study. Int J Adolesc Med Health. 2015;27:235-7.

16 Sher L, Bierer LM, Makotkine I, Yehuda R. The effect of oral dexamethasone administration on testosterone levels in combat veterans with or without a history of suicide attempt. J Psychiatr Res. 2020 Nov 20;S0022-3956(20)31093-1. doi: 10.1016/j.jpsychires.2020.11. 034. Online ahead of print.

17 Sher L, Grunebaum MF, Sullivan GM, Burke AK, Cooper TB, Mann JJ, et al. Testosterone levels in suicide attempters with bipolar disorder. J Psychiatr Res. 2012;46:1267-71.

18 Stefansson J, Chatzittofis A, Nordström P, Arver S, Åsberg M, Jokinen J. CSF and plasma testosterone in attempted suicide. Psychoneuroendocrinology. 2016;74:1-6.

19 Sher L. Both high and low testosterone levels may play a role in suicidal behavior in adolescent, young, middle-age, and older men: a hypothesis. Int J Adolesc Med Health. 2016 Jun 7;30(2):/j/ijamh. 2018.30.issue-2/ijamh-2016-0032/ijamh-2016-0032.xml. doi: 10.1515/ ijamh-2016-0032.

20 Akkaya-Kalayci T, Vyssoki B, Winkler D, Willeit M, Kapusta ND, Dorffner G, et al. The effect of seasonal changes and climatic factors on suicide attempts of young people. BMC Psychiatry. 2017; 17:365.

21 Nassar GN, Leslie SW. Physiology, testosterone. StatPearls [Internet]. 2021 Jan 19 [cited 2021 Jun 29]. www.ncbi.nlm.nih.gov/books/ NBK526128/.

22 Geraghty AC, Kaufer D. Glucocorticoid regulation of reproduction. Adv Exp Med Biol. 2015;872:253-78.

23 Whirledge S, Cidlowski JA. Glucocorticoids, stress, and fertility. Minerva Endocrinol. 2010;35:109-25.

24 Collins KJ, Few JD, Forward TJ, Giec LA. Stimulation of adrenal glucocorticoid secretion in man by raising the body temperature. J Physiol. 1969;202:645-60.

25 Kanikowska D, Roszak M, Rutkowski R, Sato M, Sikorska D, Orzechowska Z, et al. Seasonal differences in rhythmicity of salivary cortisol in healthy adults. J Appl Physiol (1985). 2019;126: 764-70. 
26 Kanikowska D, Sugenoya J, Sato M, Shimizu Y, Inukai Y, Nishimura N, et al. Seasonal variation in blood concentrations of interleukin-6, adrenocorticotrophic hormone, metabolites of catecholamine and cortisol in healthy volunteers. Int J Biometeorol. 2009;53:479-85.

27 Brådvik L. Suicide risk and mental disorders. Int J Environ Res Public Health. 2018;15:2028.
28 Finkelstein $\mathrm{Y}$, Macdonald EM, Hollands S, Sivilotti ML, Hutson JR, Mamdani MM, et al. Risk of suicide following deliberate self-poisoning JAMA Psychiatry. 2015;72:570-5.

29 Beautrais AL. Further suicidal behavior among medically serious suicide attempters. Suicide Life Threat Behav. 2004;34:1-11. 